\title{
Duodenal diverticula and jaundice
}

\author{
I. L. CRAFT* \\ F.R.C.S. \\ G. P. BurNS \\ F.R.C.S. \\ Formerly House Surgeon \\ Senior Registrar
}

Department of Surgery, Hammersmith Hospital, London

Diverticula of the small bowel occur most commonly in the duodenum; two-thirds of these are found in the second part. In this site $88 \%$ (Jones \& Merendino, 1960) arise along the concave border, usually near the ampulla of Vater. Jaundice occurs more frequently in those with a diverticulum in this situation than in the general population. This is because of complications that may arise from the diverticulum, or from gall stones and gall bladder disease, with which there is a close association (Landor, 1966).

We describe here a patient in whom jaundice resulted from obstruction of the common bile duct by a diverticulum.

\section{Case report}

Mrs F.B., aged 54, attended the Hammersmith Hospital in March 1960 with a history of three attacks of severe upper abdominal pain suggestive of gall-bladder disease, during 12 years. A cholecystogram was performed and was normal. Two years previously she had jaundice which was not investigated and this resolved spontaneously.

On 6 August 1965 she was admitted because of jaundice and irritation of the skin, pale stools and dark urine. The jaundice, which was fading, had been present for 1 week. She also complained of severe epigastric pain with vomiting, each morning for 9 months. The pain, which lasted about $15 \mathrm{~min}$ and which was relieved by the vomiting, had recently increased in severity and become localized to the right subcostal region. Upper lumbar backache was also present. She had a moderate intake of alcohol but had not taken any drugs or received any injections.

On examination she was afebrile and jaundiced. There were scratch marks on her skin and the liver edge was palpable two finger-breadths below the costal margin. It felt smooth and was not tender.

A diagnosis of obstructive jaundice was made.

\footnotetext{
* Present appointment: Surgical Registrar, Westminster Hospital, London.
}

Investigations. Haemoglobin $108 \%$; white blood count $6000 / \mathrm{mm}^{3}$; platelets $118,000 / \mathrm{mm}^{3}$; prothrombin time $21 \mathrm{sec}$. The electrolytes were normal and the blood urea less than $10 \mathrm{mg} / 100 \mathrm{ml}$. Serum total and differential protein and amylase levels were normal. The urine contained bilirubin but no urobilinogen. The stools were negative for occult blood. Liver function tests - bilirubin $4.2 \mathrm{mg} /$ $100 \mathrm{ml}$, alkaline phosphatase 23 K.A. units, thymol turbidity 5 units, zinc sulphate 5 units, isocitrate dehydrogenase $25 \mathrm{I}$. units, 5-nucleotidase $>150 \mathrm{I}$. units.

These results suggested that, besides someo parenchymal liver damage secondary to biliary obstruction, there was evidence of cholangitis (Hobbs, Campbell \& Scheuer, 1966).

Progress. The jaundice subsided spontaneously and, over the course of 2 weeks, the liver function tests returned to normal. A barium meal was performed on 13 August 1965 and showed a diverticulum arising from the concavity of the second part of the duodenum (Figs. 1 and 2). This retained some barium at $3 \mathrm{hr}$, at which time barium was seen in the colon. There was no evidence of a pancreatic mass or of varices. When the serum bilirubin level had reverted to normal a cholecystogram was performed and the gall bladder was seen to function normally. No gall stones were seen. Subsequently an intravenous cholangiogram was performed. The common bile duct measured $10 \mathrm{~mm}$ in diameter in its supraduodenal portion and between 6 and $7 \mathrm{~mm}$ in diameter in the upper pancreatic portion, but the lower end of the duct was not clearly visualized and no definite abnormality was noted.

On 25 August 1965 the patient underwent laparotomy.

Operation. A right paramedian incision was made. It was found that the liver was not enlarged and there was no evidence of cirrhosis. There was a small indurated area in the head of the pancreas 


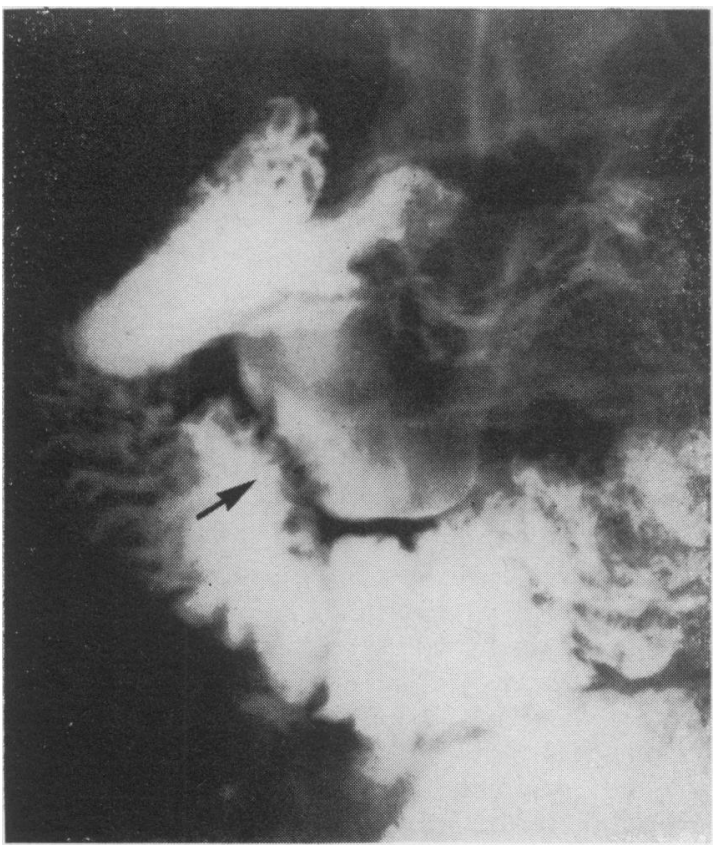

FIG. 1. Duodenal loop showing diverticulum on barium meal examination.

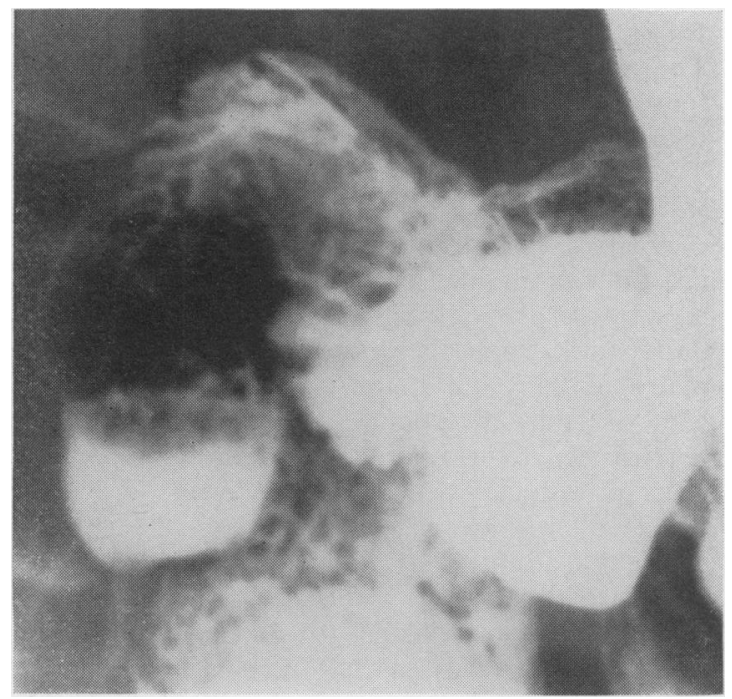

FIG. 2. Oblique view showing barium within diverticulum.

and a biopsy was normal on frozen section. There were several small diverticula in the jejunum. The second part of the duodenum was mobilized by Kocher's manoeuvre and a diverticulum was found arising from the postero-medial aspect of the second part of the duodenum (Fig. 3), which on distension measured approximately $3 \mathrm{~cm}$ in diameter. Following a duodenotomy its neck, which admitted the tip of the little finger, was found to be situated immediately adjacent and posterior to the ampulla of Vater (Fig. 4). A bacteriological swab of the contents of the diverticulum yielded a few colonies of $E$. coli.

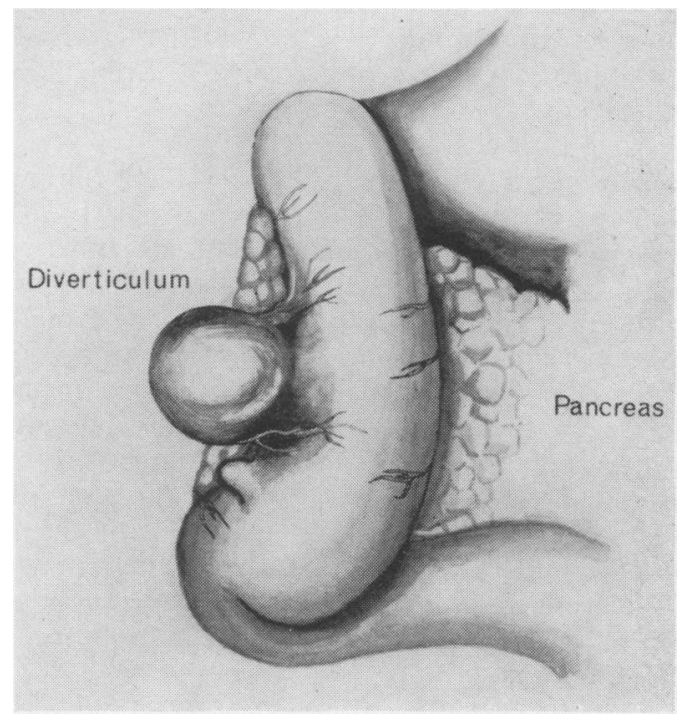

FIG. 3. Diagram of operation findings after mobilization of descending part of duodenum medially.

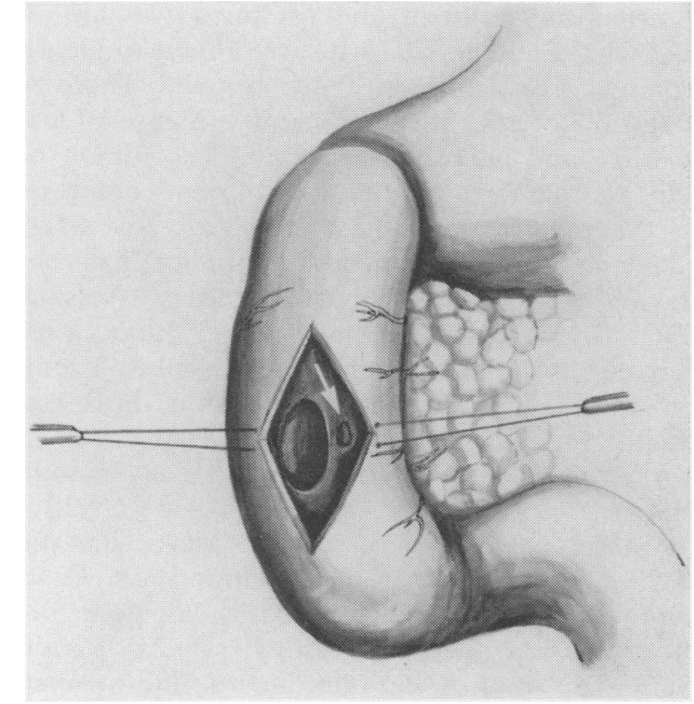

FIG. 4. The neck of diverticulum is seen in close proximity to the ampulla of Vater - the latter is arrowed. 
The common bile duct, which was not grossly dilated, was opened and explored, but no abnormality was found. The ampulla was dilated to accept a $6 / 9$ bougie. Two further small duodenal diverticula were found at the junction of the second and third parts of the duodenum. Owing to the intimate relationship of the neck of the diverticulum to the ampulla, no direct surgical approach was made upon the diverticulum. A cholecyst-jejunostomy with an entero-entero anastomosis was performed and a liver biopsy was taken.

Histology. This was reported as follows: 'Sections of the liver show a normal pattern. The liver cells show fatty changes but are otherwise normal. The portal tracts are widened by fibrous tissue showing a moderate infiltration by lymphocytes, plasma cells and occasional eosinophils. There is iron in the Kupffer cells and in macrophages in the portal tracts. There is bile duct proliferation but no evidence of cholangitis or bile thrombi now. The appearances are those of past biliary obstruction. The iron excess in the liver is probably associated with the alcohol ingestion.'

When seen 5 months after the operation the patient was symptom free. She has since been lost to follow up.

\section{Discussion}

Diverticula in relation to the ampulla of Vater usually extend posteriorly to the common bile duct and the pancreas, and may even be embedded in the latter. In 1893 Rosenthal (in Odgers, 1930) reported the autopsy findings on a woman who died with jaundice, and who was found to have an inflamed diverticulum near the ampulla. There was dilatation of the bile ducts and evidence of pancreatitis, and he concluded that the common bile duct and pancreatic ducts had been compressed by the diverticulum. That peri-Vaterian diverticula may cause obstructive jaundice has been previously reported (Wilbur, Reimer \& Cressman, 1956; Jones \& Merendino, 1960; Lane, 1960; Hartley, 1962 ; Whitcomb, 1964 ; Neill \& Thompson, 1965 ; Landor, 1966; Landor \& Fulkerson, 1966).

At laparotomy in our patient, as in other reported cases (Wilbur et al., 1956; Neill \& Thompson, 1965), there was no gross dilatation of the bile ducts or pathology within them. Others have reported gross dilatation of the ducts without intra-lumenal disease (Hartley, 1962; Landor. 1966). The state of the bile ducts found at operation is dependent on the degree of obstruction present at that time, and in the patient described above they were not dilated because by then there was no longer any jaundice, and the liver function tests had reverted to normal. It has been suggested that obstruction to the common bile duct may result from pressure of a diverticulum distended with food or because of inflammation, from spasm of the sphincter of Oddi secondary to these factors, or from inflammation of the duodenal papilla. In the case reported by Whitcomb (1964) there was evidence of diverticulitis. It is possible that cholangitis secondary to bacterial contamination of a diverticulum may be a contributory factor, for in this patient $E$. coli was cultured from a swab of the contents of the diverticulum taken at laparotomy. Deficiency of the muscle layer in the wall of a diverticulum leads to stasis, as seen by retention of barium on radiological examination, and this may predispose to infection.

Most duodenal diverticula are asymptomatic but they may present with symptoms suggestive of gall bladder disease, peptic ulceration or pancreatitis besides those of complications which include inflammation, perforation, haemorrhage, obstruction to the common bile duct, pancreatitis and enterolith formation. Symptoms suggestive of gall bladder disease, such as occurred in our patient, are a common presentation and Lane (1960) noted that in $31 \%$ of his series a previous cholecystectomy had been performed. In many of these no abnormal pathology or gall stones were found. The persistence of symptoms after a cholecystectomy, even for proven gall stones, should lead one to suspect the presence of a duodenal diverticulum.

There is, however, a close association with gall stones. Landor \& Fulkerson (1966) found 31\% of their cases with diverticula in the second part of the duodenum had evidence of gall stones compared with $13.4 \%$ with diverticula in the distal duodenum. Jones \& Meredino (1960) quoted a figure of $22 \%$ but made no correlation with the site of the diverticula. Jaundice may occur secondarily to gall stones especially when they are intra-ductal. They have been previously reported within a peri-Vaterian diverticulum (Hare \& Cattell, 1944). Landor \& Fulkerson (1966) postulated that peri-Vaterian diverticula might themselves be responsible for the formation of the calculi, and suggested that if obstruction to the common bile duct can produce jaundice, then lesser degrees of obstruction may cause stasis of bile and stone formation.

Surgical excision is the procedure of choice for a diverticulum causing jaundice but this may not be easy if it is embedded in the pancreas or adherent to the common bile duct. After mobilizing the descending part of the duodenum, dissection may be aided by opening the common duct and passing a bougie through into the duodenum, 
and if necessary performing a duodenotomy, so the common bile duct is not damaged. In our patient a short-circuit was performed and not excision because of the difficulty of operation. Cattell \& Mudge (1952) reported an $8 \%$ mortality rate for operations on duodenal diverticula, but in the recent series of Landor \& Fulkerson (1966) six cases were operated on without a fatality.

\section{Summary}

The association of jaundice with duodenal diverticula is discussed and a case with obstructive jaundice due to a peri-Vaterian diverticulum is reported. Cholangitis, secondary to bacterial contamination of the diverticulum, may have been a contributory factor.

\section{Acknowledgment}

We would like to thank Mr R. H. Franklin for permission to publish this case.

\section{References}

Cattell, R.B. \& Mudge, T.J. (1952) The surgical significance of duodenal diverticula. New Engl. J. Med. 246, 317.

HARTLEY, F.K. (1962) Biliary obstruction: A case of common bile duct obstruction as a complication of a duodenal diverticulum. J. Kans. med. Soc. 63, 51.

Hobbs, J.R., Campbell, D.M. \& Scheuer, P.J. (1966) The clinical value of serum 5 nucleotidase assay. Enzym. Biol. Clin. 6, 182.

Jones, T.W. \& Merendino, K.A. (1960) The perplexing duodenal diverticulum. Surgery, 48, 1068.

LANDOR, J.H. (1966) Diverticula of the small intestine. Missouri Med. 68, 42.

LANDOR, J.H. \& FulKerson, C.C. (1966) Duodenal diverticula. Relationship to biliary tract disease. Arch. Surg. 93, 182.

LANE, D. (1960) Primary duodenal diverticula and their problems. Aust. N.Z. J. Surg. 30, 63.

Neill, S.A. \& Thompson, N.W. (1965) The complications of duodenal diverticula and their management. Surg. Gynec. Obstet. 120, 1251.

Rosenthal: in Odgers, P.N.B. (1930) Duodenal diverticulosis. Brit. J. Surg. 17, 592.

Wнiтсомв, J.G. (1964) Duodenal diverticulum; A clinical evaluation. Arch. Surg. 88, 275.

Wilbur, B.C., Reimer, G.W. \& Cressman, R.D. (1956) Duodenal diverticula in common duct disease. Amer. $J$. Surg. 92, 318.

\title{
Solitary myeloma of the skull, causing bilateral exophthalmos
}

\author{
I. J. T. DAVIES* \\ M.B., M.R.C.P. \\ Medical Registrar, \\ Whittington Hospital, London, N.19
}

SOLITARY myeloma (plasmocytoma) of bone rarely occurs. In a review of the literature, Raven \& Willis (1949) found nineteen authenticated cases, sixteen of which were males. The commonest bone to be involved was the femur and the next commonest the humerus. Involvement of the skull was not recorded. The following case illustrates a solitary myeloma which involved both orbits, causing bilateral exophthalmos.

\section{Case report}

A woman aged 73 presented in 1963 with leftsided exophthalmos and a soft tissue mass in the region of the left temporalis muscle. She had rapidly developed visual loss in both eyes. Examination revealed pulsating exophthalmos with primary optic atrophy on the left and a pulsatile tumour in the region of the left temporalis muscle. The tumour was $3 \times 2 \mathrm{~cm}$ and was soft. The edges of the skull could be felt surrounding it.

\footnotetext{
* Present address: University College Hospital, Gower Street, London, W.C.1.
}

$\mathrm{X}$-ray of the skull showed a large defect in the frontal bone with destruction of part of the sphenoid. There was also destruction of the zygoma and left side of the orbit.

A clinical diagnosis of secondary carcinoma was made, although no primary site could be found. Routine blood count was normal, and the sedimentation rate was $70 \mathrm{~mm}$ in $1 \mathrm{hr}$. She received a course of X-ray therapy to the pulsatile swelling with considerable regression of the mass.

In May 1966 she was found to have severe bilateral exophthalmos and optic atrophy (Fig. 1). Pupillary light reflexes were absent. The swelling over the left temporalis muscle had not recurred. The sedimentation rate was $90 \mathrm{~mm}$ in $1 \mathrm{hr}$, there was no myeloma band in an electrophoretic strip of the plasma proteins and at no time was there any Bence Jones protein in the urine. X-ray of the skull showed that osteolytic bone destruction had extended to involve both orbits. Three months after admission she developed bronchopneumonia and died. 